\title{
Field experimental study on the effect of thawed depth of frozen alpine meadow soil on rill erosion by snowmelt waterflow
}

\author{
XIAONAN SHI ${ }^{1}$, Fan Zhang ${ }^{2}$, Tingwu Lei ${ }^{3}$, Chen Zeng $^{1}$, Li Wang ${ }^{1}, \mathrm{XIONG} \mathrm{XIAO}^{1}$, and \\ Guanxing Wang ${ }^{1}$ \\ ${ }^{1}$ Institute of Tibetan Plateau Research Chinese Academy of Sciences \\ ${ }^{2}$ Institute of Tibetan Plateau Research \\ ${ }^{3}$ China Agricultural University
}

September 16, 2020

\begin{abstract}
Soil erosion by snow or ice melt waterflow is an important type of soil erosion in many high-altitude and high-latitude regions. The snowmelt waterflow erosion process, affected by soil freeze and thaw, is highly dynamically variable. In this study, field experiments were conducted to investigate the effects of thawed depth of frozen soil profile on snowmelt waterflow erosion of alpine meadow soil in the spring. The experiments involved five thawed depths from 0 to 100 mm under two snowmelt waterflow rates of $3 \mathrm{~L} / \mathrm{min}$ and $5 \mathrm{~L} / \mathrm{min}$. The unthawed soil or shallow-thawed depth of $10 \mathrm{~mm}$ significantly altered the runoff and sediment production mechanism, including a significant delay of the runoff generation time and change of hydrograph and sedigraph. When the soil was frozen, the topsoil was structured with large open voids, to retain water and impede flow. This resulted in runoff generation time that was greatly lagged and soil erosion in the initial stage that was inhibited. The relationship curve of runoff and sediment concentration showed two-stage patterns that characterized a limited sediment supply in the early stage and hydrodynamic-controlled processes in the later stage. The deep-thawed cases ([?] 30 mm) showed similar hydrograph and sedigraph patterns with unfrozen soil condition. The findings of this study provide guidance for the future improvement of erosion model of partially thawed soil. Keywords: snowmelt waterflow erosion; thawed soil depth; soil freeze and thaw; runoff generation; sediment rating curve
\end{abstract}

Field experimental study on the effect of thawed depth of frozen alpine meadow soil on rill erosion by snowmelt waterflow

Xiaonan Shi ${ }^{\mathrm{a}, \mathrm{b}}, 11^{*}$ Corresponding author. E-mail address:shixiaonan@itpcas.ac.cn(X. Shi), Fan Zhang ${ }^{\mathrm{a}, \mathrm{b}, \mathrm{c}}$, Tingwu Lei ${ }^{\mathrm{d}}$, Chen Zeng ${ }^{\mathrm{a}}$, Li Wang ${ }^{\mathrm{a}, \mathrm{c}}$, Xiong Xiao ${ }^{\mathrm{a}, \mathrm{c}}$, Guanxing Wang ${ }^{\mathrm{a}, \mathrm{c}}$

${ }^{a}$ Key Laboratory of Tibetan Environment Changes and Land Surface Processes, Institute of Tibetan Plateau Research, Chinese Academy of Sciences (CAS), Beijing, 100101, China

${ }^{b}$ CAS Center for Excellence in Tibetan Plateau Earth Sciences, Beijing, 100101, China

${ }^{c}$ University of Chinese Academy of Sciences, Beijing, 100101, China

${ }^{d}$ College of Water Resources and Civil Engineering, China Agricultural University, Beijing 100083, China

Abstract: Soil erosion by snow or ice melt waterflow is an important type of soil erosion in many highaltitude and high-latitude regions. The snowmelt waterflow erosion process, affected by soil freeze and thaw, is highly dynamically variable. In this study, field experiments were conducted to investigate the effects of thawed depth of frozen soil profile on snowmelt waterflow erosion of alpine meadow soil in the spring. The experiments involved five thawed depths from 0 to $100 \mathrm{~mm}$ under two snowmelt waterflow rates of 3 
$\mathrm{L} / \mathrm{min}$ and $5 \mathrm{~L} / \mathrm{min}$. The unthawed soil or shallow-thawed depth of $10 \mathrm{~mm}$ significantly altered the runoff and sediment production mechanism, including a significant delay of the runoff generation time and change of hydrograph and sedigraph. When the soil was frozen, the topsoil was structured with large open voids, to retain water and impede flow. This resulted in runoff generation time that was greatly lagged and soil erosion in the initial stage that was inhibited. The relationship curve of runoff and sediment concentration showed two-stage patterns that characterized a limited sediment supply in the early stage and hydrodynamiccontrolled processes in the later stage. The deep-thawed cases ([?] $30 \mathrm{~mm}$ ) showed similar hydrograph and sedigraph patterns with unfrozen soil condition. The findings of this study provide guidance for the future improvement of erosion model of partially thawed soil.

Keywords: snowmelt waterflow erosion; thawed soil depth; soil freeze and thaw; runoff generation; sediment rating curve

Running title: Effect of thawed depth on rill erosion by snowmelt waterflow

\section{Introduction}

Soil erosion by snow or ice melt waterflow is an important type of soil erosion in high-altitude and highlatitude areas (Emmanuel et al., 2008), such as the cold regions of North America, northeastern Europe, the Antarctic Peninsula, and the Tibetan Plateau in Asia (Hayhoe et al., 1995; Seyfried and Flerchinger, 1994; Vasilyev, 1994; Ollesch et al., 2005; Golledge, 2014; Ban et al., 2017). The erosion rate during snowmelt events in some areas can reach or even exceed the rainfall erosion rate (e.g., Demidov et al., 1995; Lundekvam, 2001; Ollesch etc., 2005; Wu et al., 2018). The soil loss caused by spring snowmelt waterflow was reported to reach $90 \%$ of the annual total soil loss in the northwest Pacific, US and in the southwest of Quebec, Canada (Wischmeier et al., 1978; Vliet et al., 1991). Žabenská and Dumbrovský (2015) found that even a low amount of surface runoff can cause serious erosion in thawed soil. These results have drawn international attention to snowmelt waterflow erosion, especially in the context of global climate change. This is because warming in high-altitude and cold regions could be subject to amplified snowmelt waterflow erosion (Hinzman et al., 2005; Immerzeel et al., 2020), potentially resulting in serious ecological and environmental problems. Therefore, it is critical to understand snowmelt waterflow erosion processes and explore the mechanisms by which snowmelt waterflow aggravates erosion.

Snowmelt erosion in spring is a process driven by snowmelt waterflow and is affected by soil freeze and thaw. Therefore, the process is related to the both temperature variation and precipitation. Under the diurnal variation of air temperature, soil will show a periodic variation of freezing at night and thawing in the daytime. During cooling at night, the water in soil begins to freeze from top to bottom as heat is lost from the soil surface. As air temperature continues to drop, the water from the soil below is suctioned upwards to the frost layer to form ice layers or lenses. As ice crystals grow in the soil voids, the soil particles are pushed apart, reducing the density and degree of interlocking in the soil (Gatto et al., 2001; Ferrick and Gatto, 2005). In contrast, during warming in the daytime, the soil begins to thaw from top to bottom and the thawed depth of frozen soil gradually increases downward. During the thawing process, the soil water shifts from a frozen state to a high-moisture liquid state and is then drained downward. Gatto et al. (2001) reported that the topsoil moisture at 1.5 to $3.5 \mathrm{~cm}$ depth is about $3 \%$ higher upon thaw than it was before it froze. Higher soil moisture potentially increases surface runoff and its erosion capacity (Oztas, 2003; Ban et al., 2016). Furthermore, the strength and particle cohesion of soil also change dynamically after thaw (Formanek et al., 1984; Kok and McCool, 1990; Lawler, 1993; Jamshidi and Lake, 2015; Chow et al., 2000; Kvaerno and Oygarden, 2006; Wang et al., 2017). Consequently, the soil erosion process is variable dynamically with the freeze-thaw process (Barnes et al., 2016; Gao et al., 2019).

Many studies have recognized that freeze-thaw processes generally increase soil erodibility (e.g., Wischmeier et al., 1978; Edwards et al., 1995; Flanagan et al., 1995; Bryan, 2000; Gatto et al., 2001; Wang et al., 2020). Through laboratory measurements, Edwards et al. (1995) showed that erosion after the freeze-thaw cycle produced a mean sediment yield $25 \%$ higher than that of unfrozen soil. In the laboratory study of Van Klaveren and McCool (1998), slightly higher erodibility of thawed soils was found compared with that of 
unfrozen soil. Lentz et al. (1993) found that most erosion occurred in early spring when soil was recently thawed. For a partially thawed soil, thawed soil depth is an important factor that dynamically affects the process and product of erosion driven by snowmelt waterflow or rainfall (Sharratt et al., 2000; Gao et al., 2019; Ban et al., 2017). However, research on the dynamic influence of freeze-thaw on snowmelt waterflow erosion process is limited. The freeze-thaw effect dynamically varies with soil-surface structure, moisture, and thawing extent, which in turn affects soil erodibility and the erosivity of surface runoff (Pall et al., 1982; Bryan 2000; Ferrick and Gatto, 2005). Ban et al. (2017) conducted laboratory tests and found that the sediment concentrations were negatively correlated with thawed soil depth, while a shallower thawed depth produced higher sediment concentration than a deeper thawed depth. Fan et al. (2010) reported that the erosion rate of snowmelt waterflow was greater when the thawing depth is relatively shallow in the initial period of thawing, and the growth rate of erosion decreased in the late period of thawing. Gao et al. (2019) reported that sediment transport capacity decreased with the increase of thawed depth from 1 to $5 \mathrm{~cm}$, but it tended to be steady when the thawed depth exceeded $5 \mathrm{~cm}$. They considered this to be because the contact area between water flow and frozen layer was large for shallower thawed soil depth since the eroded rill widened laterally once the rill reached the bottom of thawed soil layer. As a result of the smaller friction coefficient of the frozen layer, less energy consumption was needed to transport sediment and a shallower thawed depth therefore has a higher sediment transport capacity (Gao et al., 2019). However, Gao et al. (2019) did not present the effect of the thawed soil depth on the hydrograph and sedigraph, namely the time process of runoff and sediment transport, which are the basis of watershed hydrological mechanism and forecast management. Van Klaveren and McCool (1998) suggested that a newly thawed soil is more erodible than at any other time. Nishimura et al. (2011) reported that soil erosion was more serious in the early thawing period and that soil loss decrease in latter stage. The current literature suggests that the effect of freeze-thaw on soil erosion is dynamic, and that the erosion effect arising from the change in thawed depth is one of the less understood aspects of the soil erosion process. Furthermore, erosion experiments driven by snowmelt waterflow are mostly conducted in soil flumes or bins in laboratory, in which the freeze-thaw process is manually controlled (e.g., Van Klaveren and McCool, 1998; Gatto, 2000; Ferrick and Gatto, 2005; Kværnø and Øygarden, 2006; Ban et al., 2017; Gao et al., 2019). Experimental field studies on snowmelt waterflow erosion under natural freeze-thaw conditions have been less documented (Shi et al., 2020).

In this study, field experiments of concentrated flow erosion on alpine meadow were conducted to characterize the effect of thawed depth on spring meltwater erosion. The study area was located in the Binggou watershed on the northern edge of the Tibetan Plateau, where alpine meadows are a natural pasture for local residents who rely on animal husbandry for their livelihood. The snowmelt waterflow erosion in spring is serious because of the heavy snow, poor vegetation coverage, and diurnal fluctuations in air temperature and in thawed depths of frozen soil (Shi et al., 2020). The objectives of this study were to study the runoff generation and sediment transport processes related to different thawed soil depths and the dynamic change between the hydrodynamic or sediment supply during the thawing process. The results of this study will contribute to understanding the mechanism behind the effect of thawed soil depth on snowmelt waterflow erosion.

\section{Methodology}

The experimental site was located in the Binggou basin, a tributary of the upper Heihe River basin on the northern slope of the Qilian Mountains in the Tibetan Plateau. The land use in the basin is mainly alpine meadow and the altitude is between 3400 and $4000 \mathrm{~m}$ a.s.l. (Yang et al., 1993), with wide distribution of seasonal frozen soil and permafrost. The average annual precipitation of the basin is $774 \mathrm{~mm}$, of which solid precipitation from March to May accounts for $20.96 \%$ (Hao et al., 2009). The average depth of seasonal snow cover is about $0.5 \mathrm{~m}$, with a maximum of $0.8-1.0 \mathrm{~m}$ (Yang et al., 1993). The snowmelt period is from April to June every year and during this period the river channel increases in water volume and becomes very turbid. According to visual observation, sediment concentration in the spring snowmelt period can even be higher than that in the summer rainfall period. Fig. 1 shows slope erosion driven by snowmelt waterflow in spring.

Fig. 1 Soil erosion along an alpine meadow hillslope in spring influenced by soil freeze-thaw and snowmelt 
waterflow.

The experimental site was positioned on a wide and straight hill slope at an altitude of $3700 \mathrm{~m}$ where seasonal frozen meadow soil is typical. The topsoil above $20 \mathrm{~cm}$ is relatively uniform and has a silty loam texture. The bulk density is $0.956 \mathrm{~g} / \mathrm{cm}^{3}$, which is lower than the density of water; the organic matter content is 68.87 $\mathrm{g} / \mathrm{kg}$; and the saturated water content is $64.17 \mathrm{~g} / \mathrm{g}$. The silty texture, low density, and high organic matter content of the soil make it susceptible to erosion.

The experiment was conducted in early May when air temperature and topsoil temperature fluctuated around $0{ }^{\circ} \mathrm{C}$ (Fig. 2), according to the observation of the automatic weather station at the top of the mountain (4100 $\mathrm{m}$ a.s.l.). Our experimental site was located at a lower altitude, so the temperatures were slightly higher than those in Fig. 2. In addition, temperature and solar radiation fluctuates greatly between positive and negative within a day, such as May 8, the test date $\left(\mathrm{Rn}, \mathrm{NET}\right.$ radiation $=-96^{\sim} 531 \mathrm{~W} / \mathrm{m}^{2}$; Ta $\left.=-4.1^{\sim} 4.3 \mathrm{degC}\right)$. During the experimental period, the depth of the frozen layer was observed to be no deeper than $40 \mathrm{~cm}$. On the selected experimental site, a group of rills were built with $20 \mathrm{~cm}$ wide, $10 \mathrm{~cm}$ deep and $400 \mathrm{~cm}$ length and a $\sim 25$ deg slope (Fig. 3). The ditching design was chosen to avoid the interference of uneven underlying surface and uneven meadow coverage. The five rills were adjacent and parallel (Fig. 3) and the initial water content, roughness, and depth of freezing layer were basically the same for all rills.

Fig. 2 The variations of air temperature and soil temperatures of different depths (Ts) at the Yakou metrological station during Mar. to Jun; where the shaded part is the time to conduct the experiments.

Fig. 3 Field experiments of concentrated flow erosion along a meadow hillslope.

The experiment comprised five thawed depth treatments conducted in five rills. Considering the poor repeatability and heavy workload of the field experiment, two parallel experimental schemes of snowmelt waterflow rates $(\mathrm{Q}=3$ and $5 \mathrm{~L} / \mathrm{min})$ were designed and carried out on the same group of rills. The experiment began 2 days after the rill was built and the $5 \mathrm{~L} / \mathrm{min}$ experiment was performed on the same group of rills one day after $3 \mathrm{~L} / \mathrm{min}$. The thawed depths $(\mathrm{Z})$ were $0,10,30,50$, and $80 \mathrm{~mm}$ at the snowmelt waterflow rate of $3 \mathrm{~L} / \mathrm{min}$ and $0,10,35,50$, and $100 \mathrm{~mm}$ at the snowmelt waterflow rate of $5 \mathrm{~L} / \mathrm{min}$. The thawed depth was controlled through adjusting the starting time of the experiments in the morning. The slight difference of thawed depth schemes between the two snowmelt flow rates was resulted from the timing of the experiment. The thawed depth was measured using a needle ruler in real time during the morning thawing. Once the desired thawed depth was reached, the flushing experiment began. Fig. 4 shows the time process of soil thawing on one of the test days (May 8th), which is the time when the designed thawed depth begins.

Fig. 4 The dynamic changes of thawed soil depth over time in the morning of an experiment day.

The snowmelt flow experiments were simulated by $0 \operatorname{deg} \mathrm{C}$ concentrated flow, which was supplied using a $1000 \mathrm{~L}$ tank containing a mixture of ice and water. The water was pumped into a steady flow sink on the upper end of the rill at a designed flow rate, and then flowed smoothly and evenly into the rill. Each experiment lasted 15 minutes, when steady runoff process and sediment concentration was reached for all the treatments. Since air temperature and temperature of meltwater were both low in the short experimental period, the influence of external temperature change on soil hydrothermal dynamics was ignored. All water samples were collected at a certain time interval of $1 \mathrm{~min}$ from the outlet for the measurement of runoff and sediment concentration, and the total runoff and total sediment load were subsequently calculated. The generation time of runoff (the interval between water entering from the top of the slope and leaving from the outlet) was recorded during the experiment. The flow velocity was measured by the dyeing method 3-4 times and an average velocity was taken. The two parallel experiment showed consistent results both in the process of runoff generation and sediment transport and in the influence of thawed soil depth (see following sections), which indicated the rationality and reliability of the experiments. Therefore, no more repeated treatments were added.

\section{Results}




\section{Runoff generation processes}

Runoff generation process from hillslopes is an important component of the hydrological response in the watershed. Two groups of experiments involving the impact of different thawed depths were conducted under two snowmelt waterflow rates $(\mathrm{Q}=3 \& 5 \mathrm{~L} / \mathrm{min})$. Fig. 5 shows the runoff generation processes at the outlet of the slope under different thawed depths. The runoff vs time curves under the five thawed depths followed two patterns. Pattern 1 is almost a straight line for the deep thawed depths (DTD; Z [?] $30 \mathrm{~mm}$ ) while Pattern_2 starts with delayed lower runoff and peaks in the middle stage for the unthawed and shallow thawed depth (STD; $\mathrm{Z}=0$ and $10 \mathrm{~mm}$ ).

Fig. 5 Runoff generation processes at the rill outlet under the effect of thawed soil depth (Z) under the two snowmelt waterflow rate conditions: (a) $3 \mathrm{~L} / \mathrm{min}$ and (b) $5 \mathrm{~L} / \mathrm{min}$.

The runoff processes for the DTD treatments $(\mathrm{Z}$ [?] $30 \mathrm{~mm})$ followed consistent straight lines, indicating that the steady outflow rate was reached as soon as runoff was generated. Since the newly thawed soil surface is nearly saturated (Wang et al., 2020), the outflow rate was close to the designed inflow rate. However, the runoff showed a slight increase when the thawed depths varied from 30 to $80 \mathrm{~mm}(\mathrm{Q}=3 \mathrm{~L} / \mathrm{min})$ or from 35 to $100 \mathrm{~mm}(\mathrm{Q}=5 \mathrm{~L} / \mathrm{min})$. Because of the presence of an impermeable frost layer under the thawing soil layer, the vertical permeability was generally impeded (Gatto et al., 2001). As a result, the infiltrated water mainly flowed out in the form of lateral subsurface flow along the frost layer. Upon thawing, the less dense and open voids topsoil will benefit the generation of water path and preferential flow, in turn, increase hydraulic conductivity and infiltration capacity (Halvorson et al., 1998). In spring, the lateral subsurface flow above the frozen layer is the main component of runoff, according to the observation of runoff plot (Xiao et al., 2020), accounting for $99 \%$ of the total runoff. When the thawed depth is shallow, the flow path in soil is conducive to the infiltration of soil water and the rapid outflow of subsurface flow along the smooth surface of the frozen layer. It could be supported by the conclusion that the preferential flow accounts for $66-82 \%$ of total infiltration in naturel woodlands (Zhang et al., 2019). Therefore, the surface runoff was relatively low for the STD.

The runoff processes for the STD treatments were different from those of the DTD treatments. The runoff generation time of STD treatments was considerably lagged with relatively low flow rate in the early stage relative to that of DTD because the topsoil was structured with large open voids, which can retain water and impede flow. The runoff gradually increased to a peak and then slightly dropped to a relatively stable value. The peak runoff was slightly higher than the levels of DTD cases, probably due to the release of early water supply accumulated during the long lagging time and of initial frozen water in the topsoil. Moreover, it was observed during the field experiments that the runoff generation time and flow velocity greatly varied among the different thawed depths.

The runoff generation time and average flow velocity were recorded during the experiment. Fig. 6 shows the runoff generation time of runoff and flow velocity at different thawed depths under the two snowmelt waterflow rates.

Fig. 6 Time taken for runoff outflow from the eroding rill and flow velocity in the rill under the effect of thawed soil depth under two snowmelt waterflow rate conditions: (a) $3 \mathrm{~L} / \mathrm{min}$ and (b) $5 \mathrm{~L} / \mathrm{min}$.

As shown in Fig. 6, the runoff generation time for STD was greatly delayed relative to that of DTD. The outflow for DTD only took 10-30 s; however, the runoff generation time for STD took 180-190 s at Q $=3$ $\mathrm{L} / \mathrm{min}$ and $60-70 \mathrm{~s}$ at $\mathrm{Q}=5 \mathrm{~L} / \mathrm{min}$. The runoff generation time for STD was lagged by 8 times and 3.5 times on average relative to that of DTD at 3 and $5 \mathrm{~L} / \mathrm{min}$, respectively. After the steady outflow, the flow velocity was also different between STD and DTD treatments (Fig. 6). The velocities for STD were smaller than those for DTD. Furthermore, for the DTD treatments, the flow velocity showed an increasing trend with the increase in thawed depth, which was consistent with the response of surface runoff in Fig. 5. 


\section{Sediment concentration variations}

Fig. 7 shows the temporal variation of sediment concentration in outflow runoff under different thawed depths at the two snowmelt waterflow rate levels. The sediment concentration vs time curves at the five thawed depths followed two different patterns. Pattern 1 approximates a power function with the exponent less than $-1\left(\mathrm{R}^{2}=0.73-0.98\right)$ where sediment concentration rapidly decreases to a stable low value for DTD. In contrast, Pattern 2 approximates a parabola with a downward opening $\left(\mathrm{R}^{2}=0.7-0.9\right)$ where sediment concentration gradually increases and then decreases for STD.

Fig. 7 Sediment concentration (SC) processes in outflow runoff under the effect of thawed soil depth (Z) under two snowmelt waterflow rate conditions: (a) $3 \mathrm{~L} / \mathrm{min}$ and (b) $5 \mathrm{~L} / \mathrm{min}$.

The variations of sediment concentration for the DTD (Z [?] $30 \mathrm{~mm})$ under the two snowmelt waterflow rate conditions followed almost the same trends (i.e., dropped rapidly to a stable low within 5 min of the experiments). During this period, as observed, the erosion rill was almost formed and stabilized. Subsequently, the water flow was in a steady state with both stable runoff rate and sediment concentration. The DTD may influence the intensity of rill erosion but not the patterns shown in the hydrograph and sedigraph in this designed scheme. In contrast, the STD greatly changed the patterns of these curves. The processes of sediment transport were inhibited at the beginning of the experiment when water filled the large open voids of the topsoil and then intensified after saturation of the thawed soil. This suggests that the STD situation can restrain soil erosion in the early stage and aggravate it in the later stage.

Under the same meltwater condition, the impact of thawed depths on the average sediment concentration was compared at two snowmelt waterflow rate levels in Fig. 8. The impacts under the two waterflow rate levels were consistent. The average sediment concentrations at STD are higher than those at DTD for the two waterflow rate levels, which suggested that the STD is more susceptible to erosion and poses a certain aggravating effect on the erosion process to some extent.

Fig. 8 The comparison of average sediment concentration (SC) between shallow thawed depth (STD) and deep thawed depth (DTD) under 2 snowmelt waterflow rate conditions $(3 \mathrm{~L} / \mathrm{min} \& 5 \mathrm{~L} / \mathrm{min})$.

\section{Discussion}

2. Difference between the two snowmelt waterflow rates

In Fig. 7, the sediment concentration for $\mathrm{Q}=5 \mathrm{~L} / \mathrm{min}$ (Fig. 7b) is less than that for $\mathrm{Q}=3 \mathrm{~L} / \mathrm{min}$ (Fig. 7a), although the runoff of the former is higher than that of the latter (Fig. 5). Under the same thawed depth, with the increase of snowmelt waterflow rate, the increase in runoff is reasonable from a common-sense perspective, but the reduction in sediment concentration seems unreasonable. For the purpose of reducing the field workload, the two groups of snowmelt waterflow rate experiments were conducted in the same series of rills, and the high snowmelt waterflow rate $(5 \mathrm{~L} / \mathrm{min})$ experiments began one day after the end of the low snowmelt waterflow rate $(3 \mathrm{~L} / \mathrm{min})$ treatments. During the first group of experiments $(3 \mathrm{~L} / \mathrm{min})$, the surface soil was relatively abundant and loose, which is easily eroded by snow melt runoff. However, the mass of loose material on the surface reduced after one scouring and therefore, when the second group of high-rate flow acted, the sediment concentrations were lower than the corresponding values of the previous low snowmelt waterflow rate $(3 \mathrm{~L} / \mathrm{min})$. At the beginning of the second group of experiments $(5 \mathrm{~L} / \mathrm{min})$ on the next day, the remaining soil on the surface encountered frost heave and dispersion and the soil water gathered upward after one night of freezing and one day of thawing. The soil surface was also structured with large open voids full of ice crystals in the morning. However, the effect of the one freeze-thaw cycle on the soil erodibility was generally considered to be lower than that of multiple high-frequency freeze-thaw cycles which have been reported in previous experimental studies (Liu et al., 2017; Wei et al., 2019).

\section{Lagging of runoff generation time and hindering of flow velocity}

For the STD soils, the runoff generation time was greatly lagged and the flow velocity was lower relative to those over the DTD soil (Fig. 6). It has been reported that the flow velocity is higher over frozen soil 
than over thawed soil because of the lower infiltration capacity (Gatto et al., 2001; Tsutsumi and Fujita, 2016), smooth surface (Ban et al., 2016), and lower runoff energy consumption (Wang et al., 2018). These conclusions were obtained from compacted soil frozen under controlled laboratory conditions. According to laboratory observations by Ban et al. (2016), the initial surface of frozen compacted soil is not very smooth, but it becomes as smooth as ice once water at $0 \mathrm{deg} C$ flows through it. In this case, the solidification time of liquid water is very short and the flow velocity on the smooth surface is relatively high. According to our field observations under natural frost heave in this study, however, the opposite situation was found. It was observed that the surface of the frozen and slightly thawed soil was abundant of ice needles or crystals within the soil voids which pushed soil aggregates and particles apart and reduced soil density (Fig. 9). When the 0degC meltwater moved within the soil voids, it was firstly solidified onto the surface of frozen soil or ice crystals. Because of the very large specific surface area of frozen soil and ice crystal in the big void structure, the amount of water to be solidified was high, and hence its outflow took a long time. As more meltwater entered, which may exceed a threshold of the thermodynamic process that drives the soil water to freeze or to saturate the open voids, the water could continue to flow forward and out. Therefore, the structure of surface soil for STD with high roughness will impede the water flow and hence hinder the runoff generation time and reduce the mean velocity.

Fig. 9 The structure of the frozen soil surface with ice crystals in the soil voids.

\section{Change in the hydrograph and sedigraph patterns}

As shown in Fig. 5 and Fig. 7, the curve patterns of hydrograph and sedigraph for the DTD soil were almost the same as those for non-frozen soil erosion in the same experiment plot in a previous study (Shi et al., 2020). However, the processes of runoff and sediment transport have been shown to greatly alter in STD soil. In the current study, both runoff and sediment concentration processes showed a tendency of inhibition followed by aggravation. Here, we will mainly discuss the influence of STD.

As discussed above, the initial frozen state of soil surface greatly hindered the flow velocity and hence the erosion process in the early stage. When the runoff within the topsoil void reached a certain threshold, more thawed topsoil was scoured and transported. The erosion resistance of partially thawed soil is considered weaker (Edwards et al., 1995; Bryan, 2000). The topsoil had higher erosion potential because of the weaker interlocking and friction of soil particle and higher moisture content (Edwards et al., 1994; Liu et al., 2017). Moreover, the thawed topsoil is often oversaturated because of the impervious effect of the frozen layer. The shallower the thawing depth, the higher the water content of the soil (Fukuda 1980; Cheng 1983). The oversaturated layer over a frozen layer with less friction force is susceptible to being scoured away. Together, these processes could contribute to the aggravation of soil erosion in the later stage. This result in this study was supported by Ban et al. (2017), whose laboratory experiment results showed that the peak sediment concentration produced by the thawed depths of 10 and $20 \mathrm{~mm}$ was higher than that of 50 and $100 \mathrm{~mm}$.

The sediment concentration variation seemed to be synchronous with the trend of runoff processes and they had almost the same peak times. The relationships between runoff and sediment concentration were analyzed through sediment rating curves (Fig. 10), which show two stages of variation for the STD treatments, i.e., an exponential stage followed by a linear stage. In the exponential stage, the sediment concentration increased exponentially with the runoff $\left(\mathrm{R}^{2}=0.85-0.92\right)$ and the increase rate of sediment concentration was relatively lower than that of runoff. In the linear stage, the sediment concentration decreased linearly with the decrease in runoff, which indicates that the erosion process in this period was mainly controlled by runoff. At the beginning of the experiment, sediment supply was relatively limited because of the shallow thawing depth, so the increase rate of sediment concentration was lower than that of runoff. In addition, the shallow frozen layer inhibited the cutting down of runoff and consequently the runoff eroded laterally. At the end of the experiment, a thin layer above $15 \mathrm{~mm}$ on the surface was scraped away and no obvious rill appeared. Therefore, the exponential stage characterizes a limited sediment supply because of the shallow thawing of the soil surface, whereas the linear stage characterizes a hydrodynamic-controlled process, similar to the general pattern of non-frozen soil erosion. In another experimental study of an artificial rainfall erosion on partially 
thawed compaction soil, we found that at shallow thawing depth $(10 \mathrm{~mm})$, the sediment concentration variation with slope length also followed a similar two-stage pattern (Gao and Shi, in preparation). The consistency of field snowmelt waterflow erosion experiment and indoor rainfall erosion experiment supported the findings of this study. Both suggested that the thawed depth of frozen soil affects the dynamic relationship between runoff and sediment. Besides, for the treatments of $5 \mathrm{~L} / \mathrm{min}$ snowmelt flow rate, the sediment concentration in rising period is lower than that in falling period for same runoff value, which is the opposite of $3 \mathrm{~L} / \mathrm{min}$ snowmelt flow rate. The lower sediment concentration in the rising period could further confirm the sediment limitation relative to the larger runoff rate in the early thawing stage. The finding of a twostage pattern (the sediment-supply-limited stage and the hydrodynamically-controlled stage) can provide guidance for improvement of erosion models of partially thawed soil in future.

Fig. 10 The relationship between sediment concentration (SC) and runoff under the effect of thawed soil depth under two snowmelt waterflow rate conditions: (a) $3 \mathrm{~L} / \mathrm{min}$ and (b) $5 \mathrm{~L} / \mathrm{min}$.

\section{Conclusions}

This work addressed the effect of thawed depth on spring meltwater erosion using field experiments of concentrated flow erosion in an alpine meadow. The results show that the unthawed soil or shallow-thawed depth of $10 \mathrm{~mm}$ altered the mechanisms of runoff and sediment transport. The results reveal initial inhibition followed by aggravation during the erosion process. When the soil is frozen or just thawed, the topsoil is structured with large open voids full of ice crystals that restrict water flow. Correspondingly, the runoff generation time was greatly lagged by 8 times and 3.5 times at the two snowmelt waterflow rates of 3 and $5 \mathrm{~L} / \mathrm{min}$, respectively, compared with the deep thawed depth treatments. When more meltwater enters and exceeds a certain threshold, the processes of runoff and sediment transport will be aggravated. This could be attributed to poor permeability and low friction of the frozen layer and intensified soil erodibility. The average flow velocity along the STD soil slope is lower than that along DTD soil slope. As for the STD soil, the rating curve between runoff and sediment concentration showed two-stage patterns of an exponential stage followed by a linear stage. The exponential stage characterizes a sediment-supply-limited process, whereas the linear stage characterizes a hydrodynamic-controlled process. Under the same snowmelt amount, the average sediment concentration in outflow water along the STD soil was relatively higher than that along the DTD soil. Therefore, STD soil considerably changes the runoff and sediment transport mechanisms, including substantially reducing runoff generation time, transforming the patterns shown on the hydrograph and sedigraph, and dynamically adjusting the sediment supply. Comparatively, the deep-thawed soil (Z [?] $30 \mathrm{~mm}$ ) did not show any strong effect on the patterns of hydrograph and sedigraph; however, its possible long-term effects should not be ignored.

\section{Acknowledgements}

This study is financially supported by the National Natural Science Foundation of China (Grant No. 41571274 and 41877081).

\section{Declaration of Competing Interest}

The authors declare that they have no known competing financial interests or personal relationships that could have appeared to influence the work reported in this paper.

\section{References}

1. Ban, Y., Lei, T., Chen, C., Yin, Z., Qian, D. 2017. Meltwater erosion process of frozen soil as affected by thawed depth under concentrated flow in high altitude and cold regions. Earth Surface Processes and Landforms 42, 2139-2146. doi: 10.1002/esp.4173.

2. Ban, Y., Lei, T., Chen, C., \& Liu, Z. 2016. Study on the facilities and procedures for meltwater erosion of thawed soil. International Soil and Water Conservation Research 142-147. http://dx.doi.org/10.1016/j.iswcr.2016.04.003.

3. Ban, Y., Lei, T., Liu, Z., \& Chen, C. 2016. Comparison of rill flow velocity over frozen and thawed slopes with electrolyte tracer method. Journal of hydrology 534: 630-637. 
https://doi.org/10.1016/j.jhydrol.2016.01.028.

4. Barnes, N., Luffman, I., Nandi, A. 2016. Gully erosion and freeze-thaw processes in clay-rich soils, northeast Tennessee, USA. GeoResJ 9-12: 67-76. http://dx.doi.org/10.1016/j.grj.2016.09.001.

5. Bryan, R. B. 2000. Soil erodibility and processes of water erosion on hillslope. Geomorphology 32(3): 385-415. https://doi.org/10.1016/S0169-555X(99)00105-1.

6. Chen, C., Ban, Y, Lei, T, Feng, R., \& Gao Y. 2018. Water flow velocity over frozen and nonfrozen black soil slopes. Hydrological Processes 32: 2231-2238. https://doi.org/10.1002/hyp.13159.

7. Chow, T. L., Rees, H. W., \& Monteith, J. 2000. Seasonal distribution of runoff and soil loss under four tillage treatments in the upper St. John River valley New Brunswick, Canada. Canadian Journal of Soil Science 80(4): 649-660.

8. Demidov, V. V., Ostroumov, V. Y., Nikitishena, I. A., et al. 1995. Seasonal freezing and soil erosion during snowmelt. Eurasian Soil Science 28: 78-87.

9. Edwards, L. M., Burney, J. R., \& Frame, P. A. 1995. Rill sediment transport on a Prince Edward Island (Canada) fine sandy loam. Soil Technology 8: 127-138.

10. Edwards, L. M., Burney, J. R., and Frame, P. A. 1994. Relationships between rill sediment and flow time varying with freezing, groundcover, compaction and slope on a Prince Edward Island (Canada) fine sandy loam. Variability in Stream Erosion and Sediment Transport. Proceedings of the Canberra Symposium. pp. 33-41.

11. Emmanuel, J. G., Douglas, W. B., \& Beth, P. S. 2008. Modern erosion rates in the High Himalayas of Nepal. Earth and Planetary Science Letters 267: 482-494. https://doi.org/10.1002/esp.1209.

12. Fan, H. M., Wu, M., \& Zhou, L. L. 2010. Study on sloping land snowmelt erosion affected by thaw depth of near-surface meadow soil. Journal of Soil and Water Conservation 24(6): 28-31 (in Chinese with English abstract).

13. Ferrick, M. G., \& Gatto, L. W. 2005. Quantifying the effect of a freeze-thaw cycle on soil erosion: laboratory experiments. Earth Surface Processes and Landforms 30(10): 1305-1326.

14. Flanagan, D., \& Nearing, M. 1995. USDA-water Erosion Prediction Project: Hillslope profile and watershed model documentation, NSERL Report No. 10. USDA-ARS National Soil Erosion Research Laboratory, West Lafayette.

15. Formanek, G. E., Mccool, D. K. \& Papendick, R. I. 1984. Freeze-thaw and consolidation effects on strength of a wet silt loam. Transactions of the ASAE 27(6): 1749-1752.

16. Gao, X., Li, F., Chen, C., Ban, Y., \& Gao, Y. 2019. Effects of thawed depth on the sediment transport capacity by melt water on partially thawed black soil slope. Land Degradation and Development 30: 84-93.

17. Gatto, L. W., Halvorson, J. J., McCool, D. K., et al. 2001. Effects of freeze-thaw cycling on soil erosion. Landscape Erosion and evolution modeling, edited by Harmon \& and Doe III, Kluwer Academic/Plenum Publishers, New York, 29-55.

18. Gatto, L.W. 2000. Soil freeze-thaw-induced changes to a simulated rill: potential impacts on soil erosion. Geomorphology 32, 147-160. https://doi.org/10.1016/S0169-555X(99)00092-6.

19. Golledge, N. R. 2014. Selective erosion beneath the Antarctic Peninsula Ice Sheet during LGM retreat. Antarctic Science 26(6): 698-707.

20. Hao, X., Wang, J., Che, T., et al. 2009. The spatial distribution and properties of snow cover in Binggou watershed, Qilian mountains: measurement and analysis. Journal of Glaciology and Geocryology 31(2): 284-292. (in Chinese with English abstract).

21. Hayhoe, H. N., Pelletier, R. G., \& Coote, D. R. 1995. Estimating snowmelt runoff erosion indixes for Canada. Journal of Soil and Water Conservation 50(2): 174-179.

22. Hinzman, L. D., Bettez, N. D., Bolton, W. R., et al. 2005. Evidence and implications of recent climate change in northern Alaska and other arctic regions. Climatic Change 72(3): 251-298. https://doi.org/10.1007/s10584-005-5352-2.

23. Immerzeel, W. W., Lutz, A. F., Andrade, M., et al. 2020. Importance and vulnerability of the world's water towers. Nature 577(7790): 364-369. https://doi-org-443.webvpn.las.ac.cn/10.1038/s41586-0191822-y. 
24. Jamshidi, R. J., \& Lake, C. B. 2015. Hydraulic and strength properties of unexposed and freeze-thaw exposed cement-stabilized soils. Canadian Geotechnical Journal 52(3), 283-294. https://doi.org/10.1139/cgj-2014-0100.

25. Kok, H., \& McCool, D. K. 1990. Freeze-thaw effects on soil strength. In Proceedings of the International Symposium on Frozen Soil Impacts on Agricultural, Range and Forest Lands, Cooley KR (ed.). US Army Cold Regions Research Engineering Laboratory Special Report 90(1): 70-76.

26. Kvaerno, S. H., \& Oygarden, L. 2006. The influence of freeze-thaw cycles and soil moisture on aggregate stability of three soils in Norway. Catena 67(3): 175-182. https://doi.org/10.1016/j.catena.2006.03.011.

27. Lawler, D. M., 1993. Needle ice processes and sediment mobilization on river banks: The River Iliston, West Glamorgan, United Kingdom. Journal of Hydrology 150: 81-114. https://doi.org/10.1016/00221694(93)90157-5.

28. Lentz, R. D., Dowdy, R. H., Rust, R. H. 1993. Soil property patterns and topographic parameters associated with ephemeral gully erosion. Journal of Soil and Water Conservation 48(4): 354-361.

29. Liu, H., Yang, Y., Zhang, K., et al. 2017. Soil erosion as affected by freeze-thaw regime and initial soil moisture content. Soil Science Society of America Journal 81: 459-467. doi:10.2136/sssaj2016.08.0271.

30. Lundekvam, H. 2001. ERONOR/ USLENO, new empirical erosion models for Norwegian conditions. International Symposium on Snowmelt Erosion and Related Problems, Oslo, Norway. 28-30.

31. Nishimura, T., Kamachi, N., Imoto, H., Mizoguchi, M., Miyazaki T. 2011. Prefreeze soil moisture and compaction affect water erosion in partially melted Andisols. Soil Science Society of America Journal 75: 691-698. doi:10.2136/sssaj2010.0226.

32. Ollesch, G., Sukhanovski, Y., Kistner, I., \& Rode, M. 2005. Characterization and modelling of the spatial heterogeneity of snowmelt erosion. Earth Surface Processes and Landforms 30(2): 197-211. https://doi.org/10.1002/esp.1175.

33. Oztas, T. \& Fayetorbay, F. 2003. Effect of freezing and thawing processes on soil aggregate stability. Catena 52(1): 1-8. https://doi.org/10.1016/S0341-8162(02)00177-7.

34. Pall, R., Dickinson, W.T., Green, D., and McGirr, R. 1982. Impacts of soil characteristics on soil erodibility: Recent developments in the explanation and prediction of erosion and sediment yield. IAHS Publ. No. 137: 39-47.

35. Seyfried, M. S., \& Flerchinger, G. N. 1994. Influence of frozen soil on rangeland erosion. In: Blackburn, W.H. et al. (Eds.), Variability of Rangeland Water Erosion Processes. Soil Sci. Soc. Am. Spec. Publ. 38: $67-82$.

36. Sharratt, B. S., Lindstrom, M. J., Benoit, G. R., Young, R. A., \& Wilts, A. 2000. Runoff and soil erosion during spring thaw in the northern US cornbelt. Journal of Soil and Water Conservation 55(4): 487-494.

37. Shi, X., Zhang, F., Wang, L., et al. 2020. Experimental study on the effects of multiple factors on spring meltwater erosion on alpine meadow slope. International Soil and Water Conservation Research 8, 116-123. https://doi.org/10.1016/j.iswcr.2020.02.001.

38. Tsutsumi, D., \& Fujita, M. 2016. Field observations, experiments, and modeling of sediment production from freeze and thaw action on a bare, weathered granite slope in a temperate region of Japan. Geomorphology 267: 37-47. https://doi.org/10.1016/j.geomorph.2016.05.020.

39. Van Klaveren, R. W., \& McCool, D. K. 1998. Erodibility and critical shear of a previously frozen soil. Transactions of the ASAE 41(5): 1315-1321.

40. Vasilyev, A. 1994. Modelling wash-off and leaching of pollutants by spring-time flow. Journal of Hydrology 159: 215-222. https://doi.org/10.1016/0022-1694(94)90257-7.

41. Vliet, L. V., \& Hall, J. W. 1991. Effect s of two crop rotations on seasonal runoff and soil loss in the Peace River region. Canadian Journal of Soil Science 71(4): 533-543.

42. Wang, E., Cruse, R. M., Chen, X. W., et al. 2017. Effects of moisture condition and freeze /thaw cycles on surface soil aggregate size distribution and stability. Canadian Journal of Soil Science 92(3): 529.

43. Wang, T., Li, P., Hou, J., et al. 2018. Response of the meltwater erosion to runoff energy consumption on loessal slopes. Water 10, 1522. doi:10.3390/w10111522. 
44. Wei, X., Huang, C., Wei, N., Zhao, H., He, Y., Wu, X. 2019. The impact of freeze-thaw cycles and soil moisture content at freezing on runoff and soil loss. Land Degradation and Development 30: 515-523.

45. Wischmeier, W. H., \& Smith, D. D. 1978. Predicting rainfall erosion losses - a guide to conservation planning. Agric Handbook, 537.

46. Wu, Y., Ouyang, W., Hao, Z., Yang, B., \& Wang L. 2018. Snowmelt water drives higher soil erosion than rainfall water in amid-high latitude upland watershed. Journal of Hydrology 556: 438-448. https://doi.org/10.1016/j.jhydrol.2017.11.037.

47. Xiao, X., Zhang, F., Zeng, C., et al. 2020. Plot-scale runoff generation processes and influence factors in permafrost-dominated catchment, Tibetan Plateau. Journal of Hydrology 124966. https://doi.org/10.1016/j.jhydrol.2020.124966.

48. Yang, Z., Yang, Z., Liang F., et al. 1993. Permafrost hydrological processes in Binggou Basin of Qilian Mountains. Journal of Glaciology and Geocryology 15(2): 235-241. (in Chinese with English abstract).

49. Žabenská, A. \& Dumbrovský, M. 2015. Changes of soil aggregate stability as a result of the effect of freeze-thaw cycles. Acta Universitatis Agriculturae et Silviculturae Mendelianae Brunensis 63(4): 1211-1218. https://doi.org/10.11118/actaun201563041211.

50. Zhang, J., Lei, T., Qu, L., Zhang, M., Chen, P., Gao, X., Chen, C., Yuan, L. 2019. Method to quantitatively partition the temporal preferential flow and matrix infiltration in forest soil. Geoderma 347: 150-159.

\section{Figure captions}

Fig. 1 Soil erosion along an alpine meadow hillslope in spring influenced by soil freeze-thaw and snowmelt waterflow.

Fig. 2 The variations of air temperature and soil temperatures of different depths (Ts) at the Yakou metrological station during Mar. to Jun; where the shaded part is the time to conduct the experiments.

Fig. 3 Field experiments of concentrated flow erosion along a meadow hillslope.

Fig. 4 The dynamic changes of thawed soil depth over time in the morning of an experiment day.

Fig. 5 Runoff generation processes at the rill outlet under the effect of thawed soil depth (Z) under the two snowmelt waterflow rate conditions: (a) $3 \mathrm{~L} / \mathrm{min}$ and (b) $5 \mathrm{~L} / \mathrm{min}$.

Fig. 6 Time taken for runoff outflow from the eroding rill and flow velocity in the rill under the effect of thawed soil depth under two snowmelt waterflow rate conditions: (a) $3 \mathrm{~L} / \mathrm{min}$ and (b) $5 \mathrm{~L} / \mathrm{min}$.

Fig. 7 Sediment concentration (SC) processes in outflow runoff under the effect of thawed soil depth (Z) under two snowmelt waterflow rate conditions: (a) $3 \mathrm{~L} / \mathrm{min}$ and (b) $5 \mathrm{~L} / \mathrm{min}$.

Fig. 8 The comparison of average sediment concentration (SC) between shallow thawed depth (STD) and deep thawed depth (DTD) under 2 snowmelt waterflow rate conditions $(3 \mathrm{~L} / \mathrm{min} \& 5 \mathrm{~L} / \mathrm{min})$.

Fig. 9 The structure of the frozen soil surface with ice crystals in the soil voids.

Fig. 10 The relationship between sediment concentration (SC) and runoff under the effect of thawed soil depth under two snowmelt waterflow rate conditions: (a) $3 \mathrm{~L} / \mathrm{min}$ and (b) $5 \mathrm{~L} / \mathrm{min}$. 

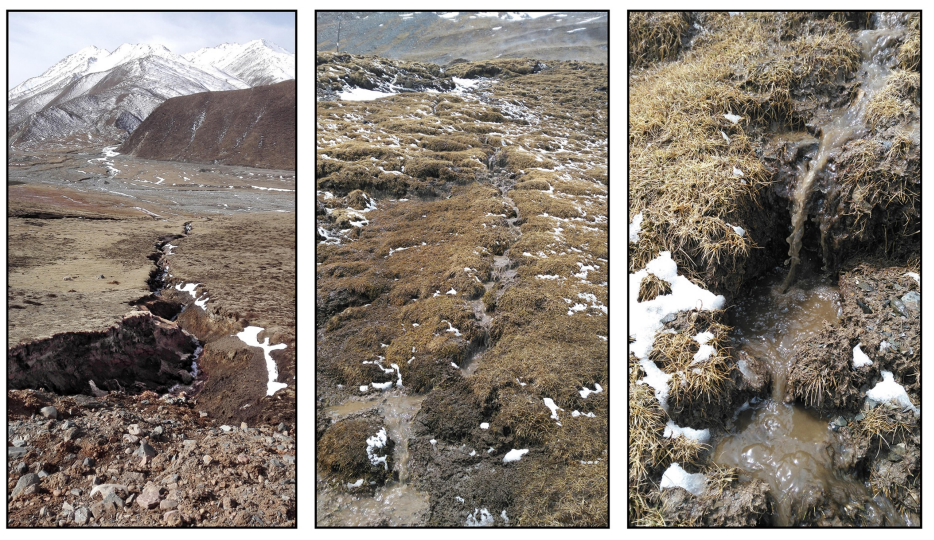

Fig. 1 Soil erosion along an alpine meadow hillslope in spring influenced by soil freeze-thaw and snowmelt waterflow. 

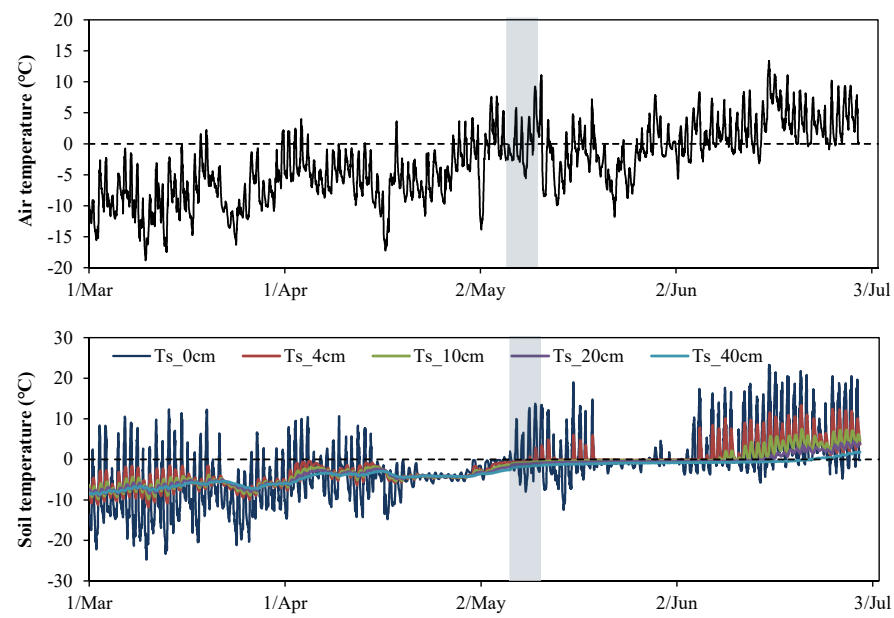

Fig. 2 The variations of air temperature and soil temperatures of different depths (Ts) at the Yakou metrological station during Mar. to Jun; where the shaded part is the time to conduct the experiments. 


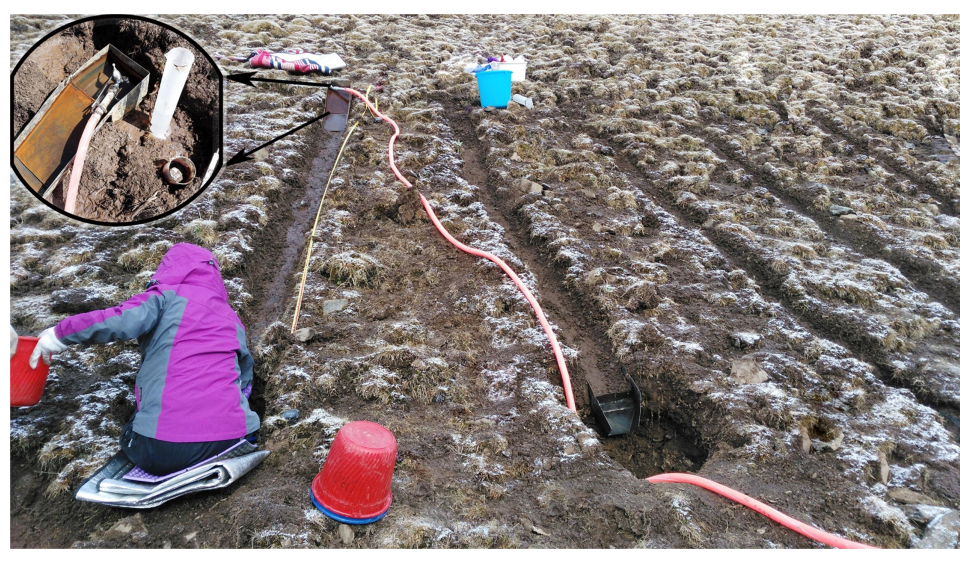

Fig. 3 Field experiments of concentrated flow erosion along a meadow hillslope. 


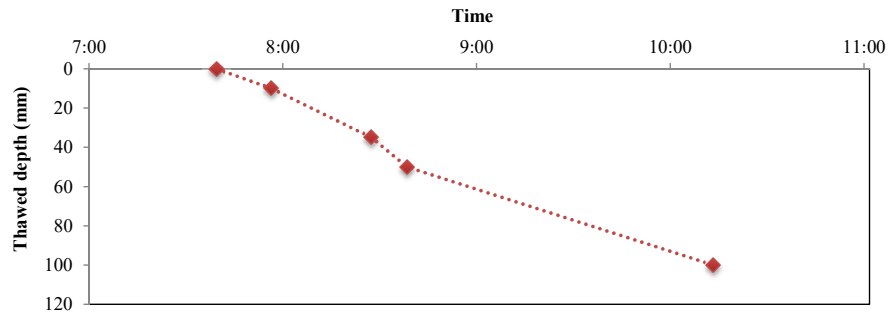

Fig. 4 The dynamic changes of thawed soil depth over time in the morning of an experiment day. 

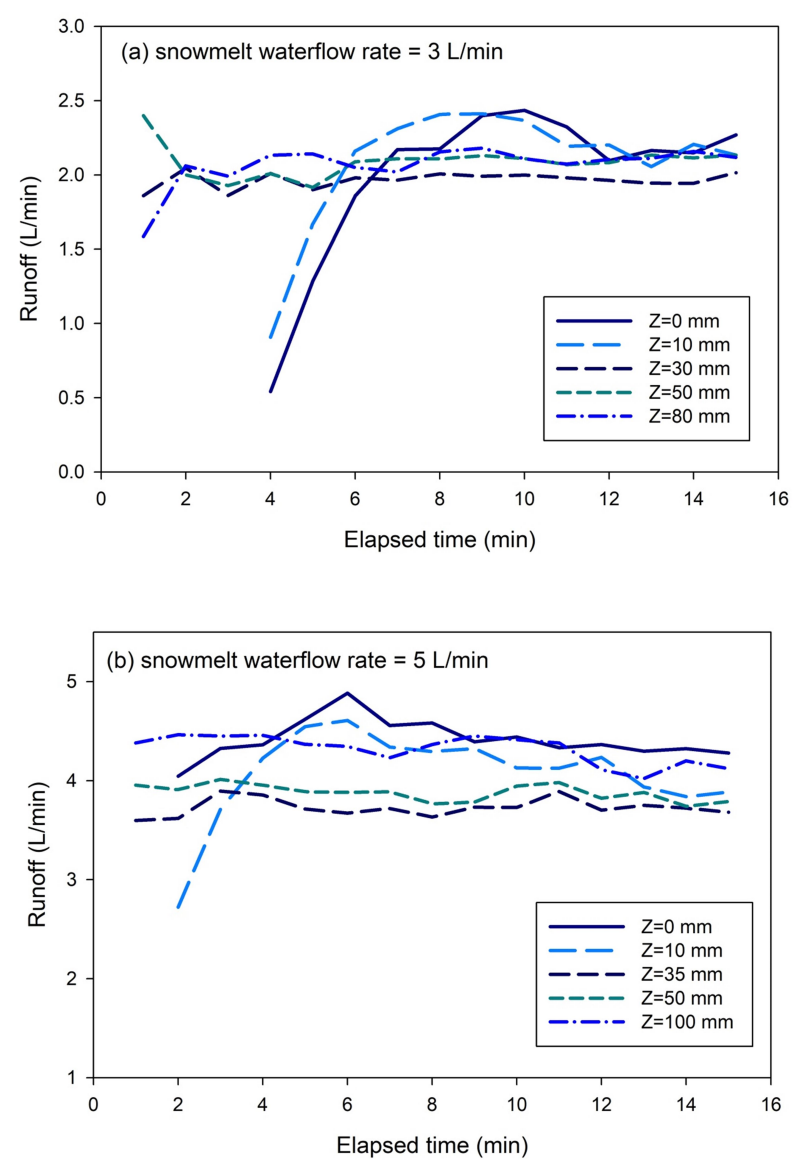

Fig. 5 Runoff generation processes at the rill outlet under the effect of thawed soil depth (Z) under the two snowmelt waterflow rate conditions: (a) $3 \mathrm{~L} / \mathrm{min}$ and (b) $5 \mathrm{~L} / \mathrm{min}$. 

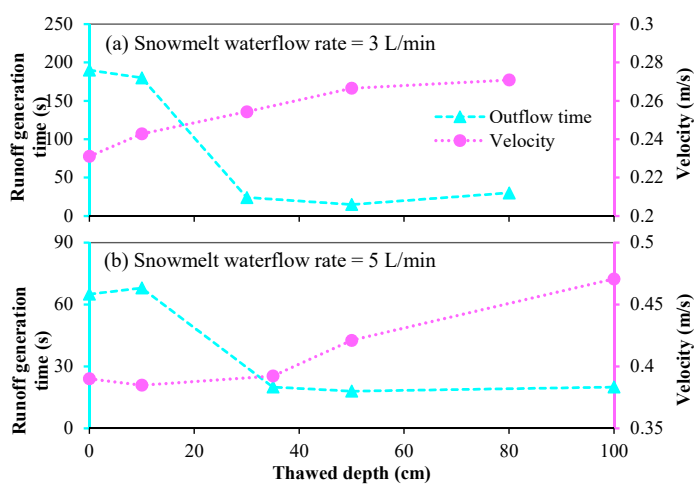

Fig. 6 Time taken for runoff outflow from the eroding rill and flow velocity in the rill under the effect of thawed soil depth under two snowmelt waterflow rate conditions: (a) $3 \mathrm{~L} / \mathrm{min}$ and (b) 5

$\mathrm{L} / \mathrm{min}$. 

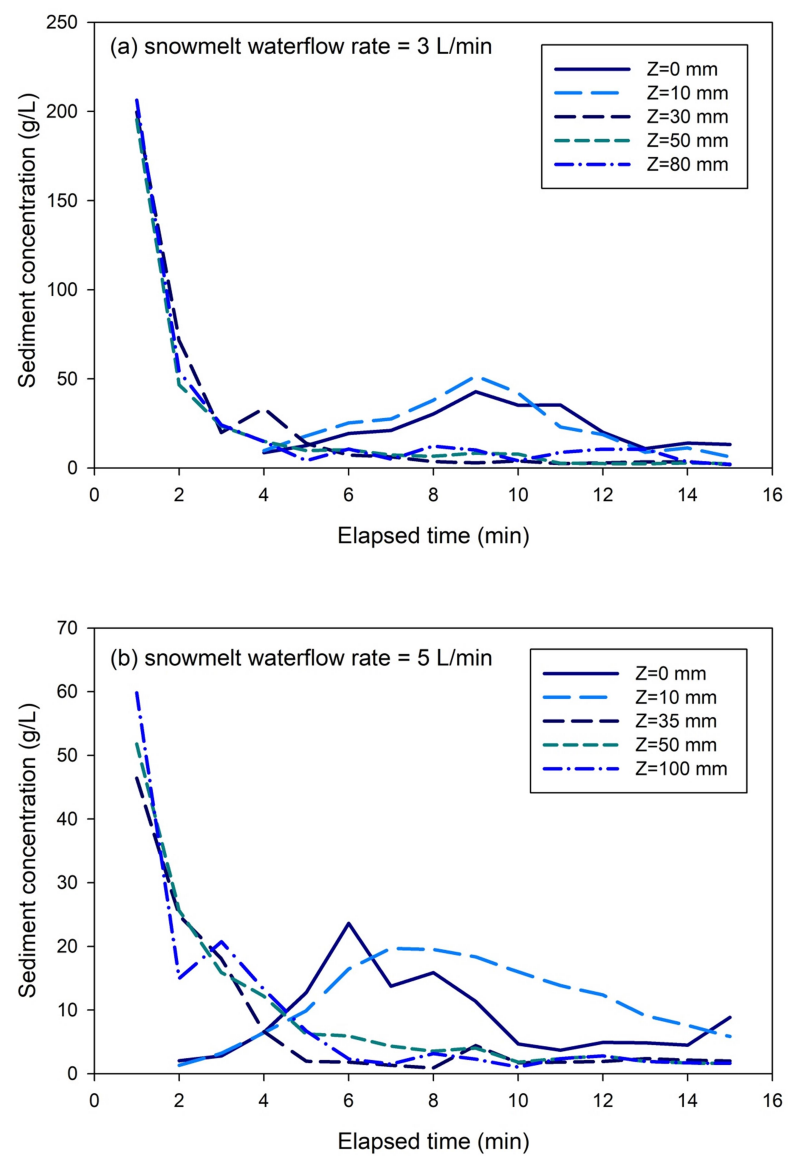

Fig. 7 Sediment concentration (SC) processes in outflow runoff under the effect of thawed soil depth (Z) under two snowmelt waterflow rate conditions: (a) $3 \mathrm{~L} / \mathrm{min}$ and (b) $5 \mathrm{~L} / \mathrm{min}$. 


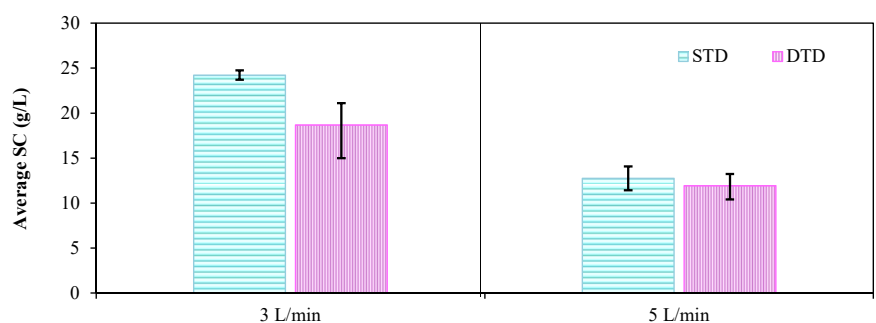

Fig. 8 The comparison of average sediment concentration (SC) between shallow thawed depth (STD) and deep thawed depth (DTD) under 2 snowmelt waterflow rate conditions ( $3 \mathrm{~L} / \mathrm{min} \& 5 \mathrm{~L} / \mathrm{min}$ ). 


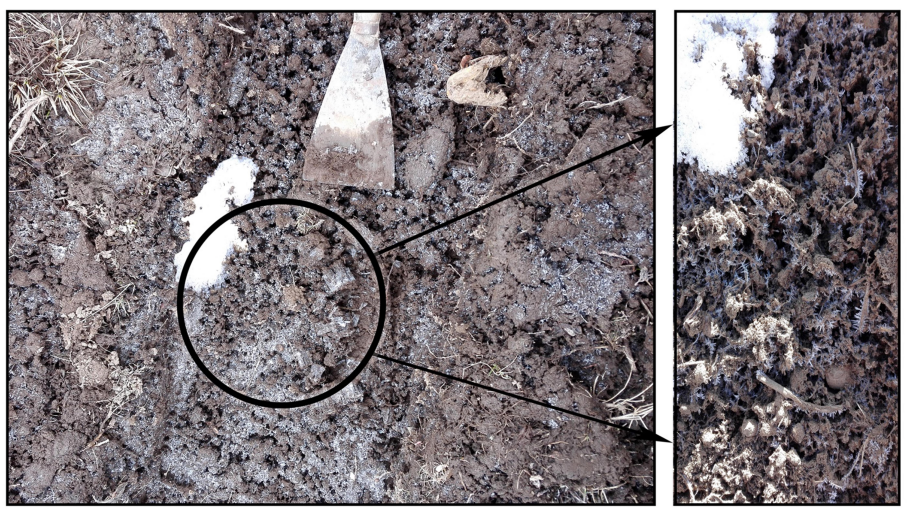

Fig. 9 The structure of the frozen soil surface with ice crystals in the soil voids. 

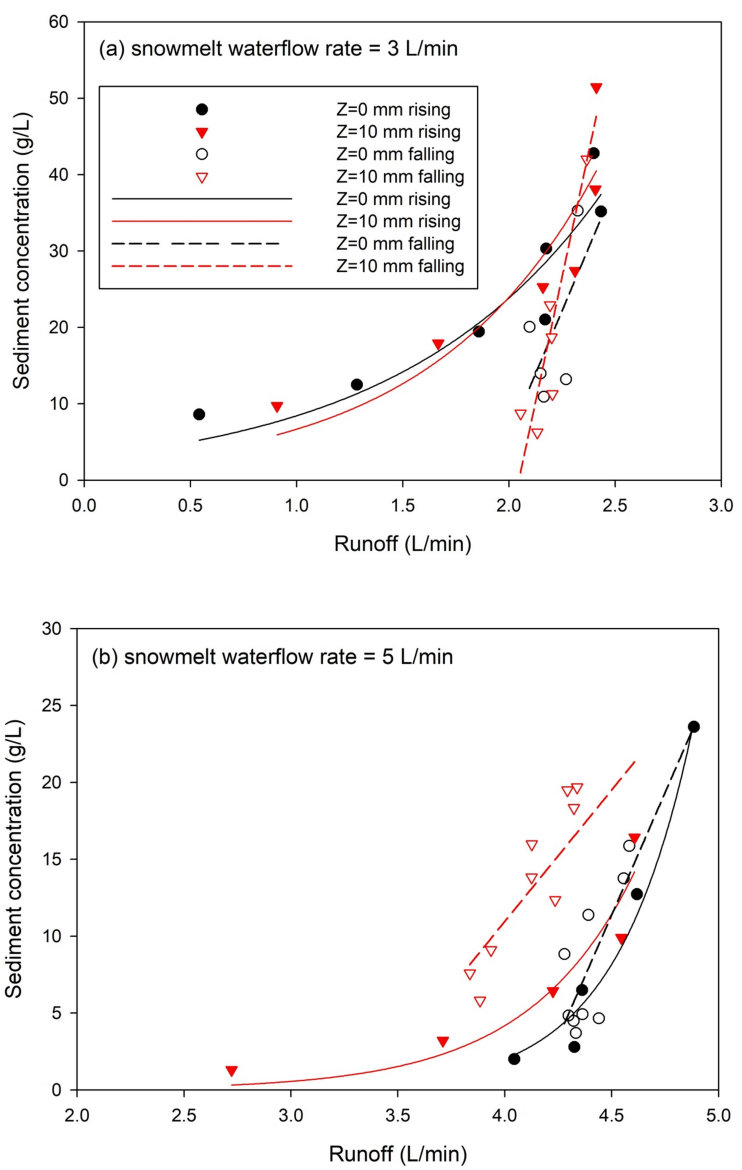

Fig. 10 The relationship between sediment concentration (SC) and runoff under the effect of thawed soil depth under two snowmelt waterflow rate conditions: (a) $3 \mathrm{~L} / \mathrm{min}$ and (b) $5 \mathrm{~L} / \mathrm{min}$. 